\title{
SWOT Analysis on Promoting GlobalGAP in China's Agricultural Production in the context of the Belt and Road Initiative
}

\author{
Li-jun $\mathrm{Li}^{1,2}$, Yi-fei Shi ${ }^{3}$ \\ ${ }^{1}$ Tianfu College of Southwestern University of Finance and Economics, Mianyang, Sichuan, China \\ ${ }^{2}$ Sichuan Modern Circulation Economic Research Center, Mianyang, Sichuan, China \\ ${ }^{3}$ Guizhou Lekesi Business Information Consulting Co., Ltd., Guiyang, Guizhou, China
}

\begin{abstract}
The progress of the Belt and Road Initiative (BRI) has not only created an unprecedented opportunity for the export of China's agricultural products but also resulted in the opportunity to promote the Global Good Agricultural Practices (GlobalGAP) in China's agricultural production. In this paper, the SWOT method was adopted to analyze the strengths, weaknesses, opportunities, and threats of promoting GlobalGAP in China's agricultural production in the context of the BRI.
\end{abstract}

\section{Introduction}

It has been nearly six years since the BRI was put forward in 2013. With its goal of enhancing China's exchanges and cooperation with European and African countries, the BRI is a major policy direction for building a new pattern of opening up for China and further integrating China's economy with that of the world ${ }^{[1]}$. Nowadays, as this road of development has been recognized by numerous countries, the economic exchanges and cooperation among the BRI participating countries have become further facilitated, playing a crucial role in the global economic recovery, and injecting new vigor and vitality into the world's economic prosperity ${ }^{[2]}$. According to Cheng Guoqiang (1999), agricultural products are classified as land-intensive and labor-intensive products, the latter enjoying an absolute advantage in China's agricultural exports ${ }^{[3]}$.

In 1997, against the backdrop of growing concerns about food safety, the EUREP proposed the EUREPGAP standard and set up a special secretariat as the overseer of the GAP standard to promote the practical application of the standard and launch relevant certification activities. Due to the conformity of its concept to the movement towards further global trade development, EUREPGAP was quickly recognized by producers and retailers worldwide and became a global standard ${ }^{[4]}$. On the 8th annual meeting held in Bangkok, Thailand in September 2007, FoodPLUS saw EurepGAP changed to GlobalGAP ${ }^{[5]}$. As a global standard, GlobalGAP certification covers the entire process from planting to harvesting (note: processing is also covered for tea industry) of agricultural products, with requirements in five areas: food safety(Safety evaluation), traceability, environmental protection, occupational health and safety, and animal welfare. This standard not only helps in achieving the purpose of controlling hazards in the area of food safety but also takes into account the requirements of sustainable development. The product categories covered by this standard were quite complete since cultural and legal requirements of different regions were referred to in the preparation of the standard to adapt to agricultural globalization. In recent years, the GlobalGAP standard has been revised several times due to the changes in world food safety standards. GlobalGAP V5.2 has been enforced since February 1st this year, and several inspection requirements have been added. The system of the standard is being perfected.

In the context of the BRI, using SWOT analysis method to analyze the superiority, weakness, opportunity, and threats of promoting GlobalGAP in China's agricultural production helps bring efficiency and effectiveness to the promotion of GlobalGAP in China's agricultural production, and attracts more agricultural enterprises and cooperatives to establish GlobalGAP.

\section{Methods}

\subsection{Strengths}

\subsubsection{Eliminating trade barriers among the BRI participating countries}

The BRI participating countries are mostly developing countries whose economies are mainly based on agriculture $^{[5]}$. The countries can, according to the basis and conditions of the BRI, exchange main agricultural products, and thereby promote the development of agricultural markets. However, the standards for agricultural products varies between different countries. The circulation of agricultural products among countries 
will be hindered without the mutual recognition of the standard. GlobalGAP is leading in the world farm integrated assurance program. As a globally accepted international standard, the GlobalGAP standard has now been accepted by 135 countries. The promotion of the GlobalGAP standard and unified safety evaluation standard in China's agricultural production will enable China to become recognized by the BRI participating countries quickly, break down trade barriers, and promote China's agricultural exports.

\subsubsection{Strengthening China's economic and trade cooperation with the BRI participating countries}

The promotion of the GlobalGAP standard will enable trade barriers to be eliminated, and China's agricultural products to be exported smoothly. In this way, the upgrading of the agricultural product trade of the BRI participating countries can be facilitated.

Furthermore, the upgrading process will drive China's agricultural production, and even the development of other factors such as employment, commerce, economy and technology, and ultimately the development of the overall strength of the country. Also, with the reciprocal development brought to the BRI participating countries, the countries can be united to form a new and tightly related economic community.

\subsubsection{Safeguarding ecological and sustainable development}

By promoting the GlobalGAP standard in China's agricultural production, we can reduce the use of pesticides and fertilizers, ensure the safety of agricultural products and food, reduce the pollution of the ecological environment, maintain forest coverage rates and protect biological diversity. With reduced consumption of raw materials for producing pesticides and fertilizers, the excessive exploitation of mineral resources can be controlled, the goal of sustainable development achieved, and the earth can be protected while promoting economic development.

\subsection{Weaknesses}

\subsubsection{Insufficient agricultural infrastructure}

Although China is a major agricultural country, its cultivated area, and land quality is unevenly distributed due to its vast territory and variety of topography and landforms and, the agricultural infrastructure remains to be improved. In some plain areas, where the cultivated area is large, and the land is flat, conditions are suitable for large-scale mechanized production and modern management, and thus conducive to promoting GlobalGAP; while in most mountainous and hilly areas with difficulty to cultivate land, which still needs to be cultivated through traditional methods, conditions are not suitable for large-scale mechanized production and modern management, and thus not as suitable for promoting GlobalGAP.

\subsubsection{Challenges of agricultural production personnel}

Due to the influence of industrial division and economic development, rural young and middle-aged workers in China tend to migrate to metropolitan areas for education, training and employment, which results in a lack of corresponding technical skill and productivity. The existing body of agricultural production personnel is mainly middle-aged and older adults, who are less educated, and lack systematic professional training. The quality of agricultural production personnel directly affects the output and quality of agricultural products and a shortage of highly trained, well-qualified personnel hinders the promotion of the GlobalGAP standard.

\subsection{Opportunities}

\subsubsection{Political connectivity among BRI participating countries}

The political landscape directly affects a country's economy and culture. Under the proposal of Chinese government, the BRI participating countries have put forward various political goals of joint development on the basis of trade connectivity, such as "Connectivity Master Plan" (ASEAN), "Eurasian Economic Union" (Russia), "Intermediate Corridor" (Turkey), "Bright Road" (Kazakhstan), and "Road of Development" (Mongolia) ${ }^{[7]}$. In recent years, China has not only carried out comprehensive cooperation with Myanmar, Hungary, and other countries but also successively signed cooperation agreements ${ }^{[8,9]}$ with nearly 50 countries and international organizations. These political intercommunications will certainly bring greater opportunities to the flow of agricultural products for the BRI participating countries, and thus facilitate the promotion of GlobalGAP standard.

\subsubsection{China's policy orientation on agricultural development}

In recent years, the CPC Central Committee and the State Council have attached great importance to the structural reform of agricultural supply ${ }^{[10]}$. The General Secretary pointed out that the advance of the structural reform in agricultural supply will help improve China's comprehensive agricultural benefits and agricultural competitiveness. Therefore, at present and shortly, the promotion of the structural reform of agricultural supply will remain the direction of China's agricultural policy reform and improvement ${ }^{[10]}$. It can be thus seen that China's existing agricultural policies have created opportunities to promote the GlobalGAP standard.

\subsubsection{China's orientation towards skilled talent development}

On February 13, 2019, the State Council issued the Notice of the State Council on Issuing the Implementation Plan for the Reform of National 
Vocational Education. The Plan proposed two new tasks: first, migrant workers returning home are required to receive secondary vocational education; second, the strategy of rural revitalization should be served by cultivating rural practical talents with new professional farmers as the main body ${ }^{[11]}$. The Plan set clear goals for the development of skilled agricultural talent, defined the direction for vocational and applied universities to develop skilled agricultural talent, and provided a human resource base for the promotion of the GlobalGAP standard.

\subsection{Threats}

\subsubsection{Threats from the scale of agricultural machinery automation}

There is still a wide gap between China and more developed countries in agricultural automation. Agricultural operation in such developed countries has been completely undertaken by agricultural machinery, and more new machinery is being used in agricultural production [11]. The development of agricultural mechanization, as an important reference point, marks the transformation from traditional agriculture to modern agriculture, which is of great significance to the whole agricultural sector. It is certain that agricultural automation will be upgraded with the development of modern economy and the improvement of science and technology [12]. Therefore, the status quo of China's agricultural automation will certainly pose a threat to the promotion of the GlobalGAP standard.

\subsubsection{Threat from agricultural skilled talent resource}

With the acceleration of China's economic development, population urbanization, and aging process, the questions of who should farm and who should guide the farming community have become greater concerns ${ }^{[13]}$. Talent cultivation is the main problem facing the development of modern agriculture in China ${ }^{[14]}$. However, there is a serious shortage of skilled talent in agriculture in China, which will inevitably pose a great threat to the promotion of the GlobalGAP standard.

\section{Conclusion}

The BRI has provided opportunities for China's agricultural products to reach around the globe. However, failure to seize the opportunity under the guidance of the BRI to improve the safety and quality of China's agricultural products will hinder China's agricultural products from being introduced and appreciated by the global market. Therefore, it is of far-reaching significance to promote GlobalGAP in China's agricultural production.

\section{Fund programs}

1. General Project "Research on Key Control Points of Agricultural Product Logistics Quality and Safety in the Context of the Internet +" (No. XDLTJJ2019YB05) of the "Special Subject of Research on Modern Circulation Economy" from 2019 Social Science Research by Sichuan Modern Circulation Economic Research Center;

2. Excellent courses of School of Modern Service Management, Tianfu College, Southwestern University of Finance and Economics.

\section{References}

1. Kang, H.; Li, J. \& Zhan, D. Comprehensive ability and quality cultivation of international business talents under the Belt and Road Initiative. Education and Teaching Forum, 22, 95-96 (2019)

2. Wang, P. F. Opportunities and countermeasures of China's agricultural product circulation in the context of the Belt and Road Initiative. Journal of Social Sciences of Jilin University, 59(03), 62-69+232 (2019)

3. Cheng, G. Q. China's agricultural product trade: patterns and policies. Management World, 03 1999)

4. Yang, X. T. Certification helps China's agricultural products go abroad. Retrieved June 9 (2013)

5. Nie, K. F. GAP Construction and Countermeasure Study for Tea Enterprises. Hunan Agricultural University (2008)

6. All 279 outcomes of the first Belt and Road Summit were implemented. from https://www.ifeng.com, Retrieved April 22 (2019)

7. Yang, C. T. Transportation must go first for Belt and Road construction. from http://www.zgjtb.com, Retrieved July 5,(2017)

8. Hao, Y. G., Hao, Z. \& Zhao, C. Theoretical analysis on and realization path for national audit to serve the Belt and Road strategy . Audit \& Economy Research, 31(02), 23-32, (2016)

9. Liu, Q. J. The Leading Role of China-Africa Cooperation \& Development and the Belt and Road Initiative. School of International Studies, Renmin University of China, (2008)

10. Han, C. F. Report of the State Council on constructing a modern agricultural system and deepening the structural reform of agricultural supply.Agricultural Engineering Technology, 38(11), $1-3(2018)$

11. Notice of the State Council on Issuing the Implementation Plan for the Reform of National Vocational Education. from http://www.gov.cn,Retrieved February 13, (2019)

12. He, J. C. Analysis on the status quo and development direction of agricultural machinery automation. The Farmers Consultant, 21, 33 (2017) 
13. Jiang, Z. Who will go in for farming? - reflections on the cultivation of young professional farmers. Education and Teaching Forum, 6 (2):,85-86 (2016)

14. Zhou, Q. M. On "agricultural talent cultivation and farmer education": the way of cultivating modern agricultural talents - based on the practical experience of Hunan Agricultural University. Journal of Hunan Agricultural University, 13(4),1-3 (2012) 